\title{
Comparison of Gastroesophageal Reflux Disease Symptoms and Proton Pump Inhibitor Response Using Gastroesophageal Reflux Disease Impact Scale Questionnaire
}

\author{
So Young Jo, ${ }^{1}$ Nayoung Kim, ${ }^{1,2 *}$ Ji Hwan Lim, ${ }^{1}$ Cheol Min Shin, ${ }^{1}$ Young Soo Park, ${ }^{1,2}$ Dong Ho Lee ${ }^{1,2}$ and Hyun Chae Jung ${ }^{2}$ \\ ${ }^{1}$ Department of Internal Medicine, Seoul National University Bundang Hospital, Seongnam, Gyeonggi-do, Korea; and ${ }^{2}$ Department of Internal \\ Medicine and Liver Research Institute, Seoul National University College of Medicine, Seoul, Korea
}

\section{Background/Aims}

To compare gastroesophageal reflux disease (GERD) symptoms and response to proton pump inhibitor (PPI) in patients with erosive esophagitis (EE), non-erosive reflux disease (NERD) or functional heartburn (FH) using GERD impact scale (GIS) questionnaire.

\section{Methods}

Total 126 patients with GERD symptoms were diagnosed as EE $(n=62)$, NERD $(n=34)$ and FH $(n=30)$ by endoscopy, 24-hour esophageal pH testing and Bernstein test, prospectively. Analysis of risk factors and GIS questionnaire for GERD symptoms and quality of life were performed before and 8 weeks after PPI treatment.

\section{Results}

EE group had a higher proportion of men, frequent alcohol consumption, smoking, hiatal hernia, body mass index $\geq 25$ $\mathrm{kg} / \mathrm{m}^{2}$ and triglyceride levels $(\geq 150 \mathrm{mg} / \mathrm{dL}$ ) than the other groups (all $P<0.05)$. On the other hand, both psychiatric treatment and psychopharmacotherapy were more frequent in patients with FH than in those with EE and NERD (both $P<0.05$ ). Among GERD symptoms, chest pain was more frequent in FH group than in EE and NERD groups $(P<0.05)$. Eating problems and limitation of productive daily activities occurred frequently in FH group and NERD group, respectively. GIS after 8 week PPI treatment showed improvement in all of the GERD symptoms in EE (all $P<0.05$ ) and in acid regurgitation, epigastric pain and hoarseness in NERD group (all $P<0.05$ ). In terms of quality of life, PPI treatment improved sleep disturbance in $\operatorname{EE}(P=0.031)$ and limitation of productive activity in the NERD group $(P=0.001)$.

\section{Conclusions}

GIS questionnaire showed that different characteristics and symptoms improved after PPI therapy among patients with EE, NERD and FH, demonstrating the usefulness of the GIS questionnaire.

(J Neurogastroenterol Motil 2013;19:61-69)

Key Words

Functional heartburn; Gastroesophageal reflux; Proton pump inhibitors; Quality of life; Questionnaires

Received: September 16, 2012 Revised: November 29, 2012 Accepted: December 1, 2012

(c) This is an Open Access article distributed under the terms of the Creative Commons Attribution Non-Commercial License (http://creativecommons. org/licenses/by-nc/3.0) which permits unrestricted non-commercial use, distribution, and reproduction in any medium, provided the original work is properly cited.

*Correspondence: Nayoung Kim, MD

Department of Internal Medicine, Seoul National University Bundang Hospital, 82, Gumi-ro 173beon-gil, Bundang-gu, Seongnam, Geoynggi-do 463-707, Korea

Tel: +82-31-787-7008, Fax: +82-31-787-4051, E-mail: nayoungkim49@empas.com

Financial support: This research was supported from the Seoul National University Bundang Hospital Research fund (Grant No. 06-2011-143) and Astrazeneca Korea.

Conflicts of interest: None.

Author contributions: So Young Jo analyzed data and wrote a manuscript. Nayoung Kim designed this study, filled up the data sheet and supervised preparing manuscript. Ji Hwan Lim collected data. Cheol Min Shin and Young Soo Park made a questionnaire and performed a statistical analysis. Dong Ho Lee and Hyun Chae Jung advised design and supervised preparing manuscript. 


\section{Introduction}

In the Montreal Workshop in 2005, gastroesophageal reflux disease (GERD) was defined as a troublesome symptom or complication caused by the reflux of the gut content into the esophagus. ${ }^{1}$ Typical symptoms have been broadly divided into 2 , i.e., esophageal syndrome and extraesophageal syndrome. Heartburn and acid regurgitation were cited as the typical symptoms of reflux. GERD has been classified into erosive esophagitis (EE) and non-erosive reflux disease (NERD). GERD lowers the quality of life (QOL) and causes complications such as esophageal cancer, and has been recognized as the most common gastrointestinal disease in the Western society. ${ }^{2,3}$ In South Korea, the incidence rate is low compared to Western countries, but increasing rates provoked interest in GERD. EE has been defined as visible breaks of the lower esophageal mucosa, which is classified into A, B, C and D in accordance with Los Angeles classification. ${ }^{4}$ NERD is diagnosed when typical reflux symptoms are observed in the absence of visible breaks of the esophageal mucosa on endoscopy. ${ }^{5}$ In addition, heartburn symptom can occur in the absence of acid reflux, ${ }^{6}$ in which case Rome III criteria proposed a definition of functional heartburn $(\mathrm{FH})$ when there was no evidence of reflux by 24-hour esophageal $\mathrm{pH}$ testing or no improvement of GERD symptoms in spite of proton pump inhibitor (PPI) treatment.

In most cases GERD is chronic, and the symptoms of GERD hinder patients' lives in physical, social and mental well-being, lowering the QOL. ${ }^{8,9}$ Naturally, it became very im- portant to monitor changes in symptoms and the influence on patients' lives. ${ }^{10}$ To evaluate GERD symptoms, patient-reported GERD outcome instruments, such as the reflux disease questionnaire, ${ }^{11}$ GERD questionnaire, ${ }^{12}$ gastrointestinal symptom rating scale ${ }^{13}$ and GERD impact scale (GIS) ${ }^{14}$ have been introduced. In the case of GIS, intended to be a communication tool between patients and their physicians, QOL of patients as well as GERD symptoms can be analyzed. That is, the Pearson correlation coefficient could measure relation between the GERD symptoms and the impact of symptoms. Under this background this study was performed to analyze the GERD symptoms, QOL of patients, and the correlation of symptoms and QOL by use of the GIS questionnaire in patients with GERD symptoms categorized into EE, NERD or FH. Responses of GERD symptoms and QOL to PPI treatment were also investigated.

\section{Materials and Methods}

A total of 207 subjects with GERD symptoms were prospectively enrolled. They were given the GIS questionnaire and underwent endoscopy between July 2008 and June 2011 (Fig. 1). Among them, 81 subjects were excluded because they refused to undergo 24-hour esophageal $\mathrm{pH}$ testing and/or Bernstein test. Finally, 126 subjects were enrolled in this study who underwent upper endoscopy, Bernstein test, and 24-hour esophageal $\mathrm{pH}$ testing. This study was reviewed and approved by the Seoul National University Institutional Review Board, and the written informed consent was obtained from all participants. ClinicalTrials.gov registration number is NCT01536080.

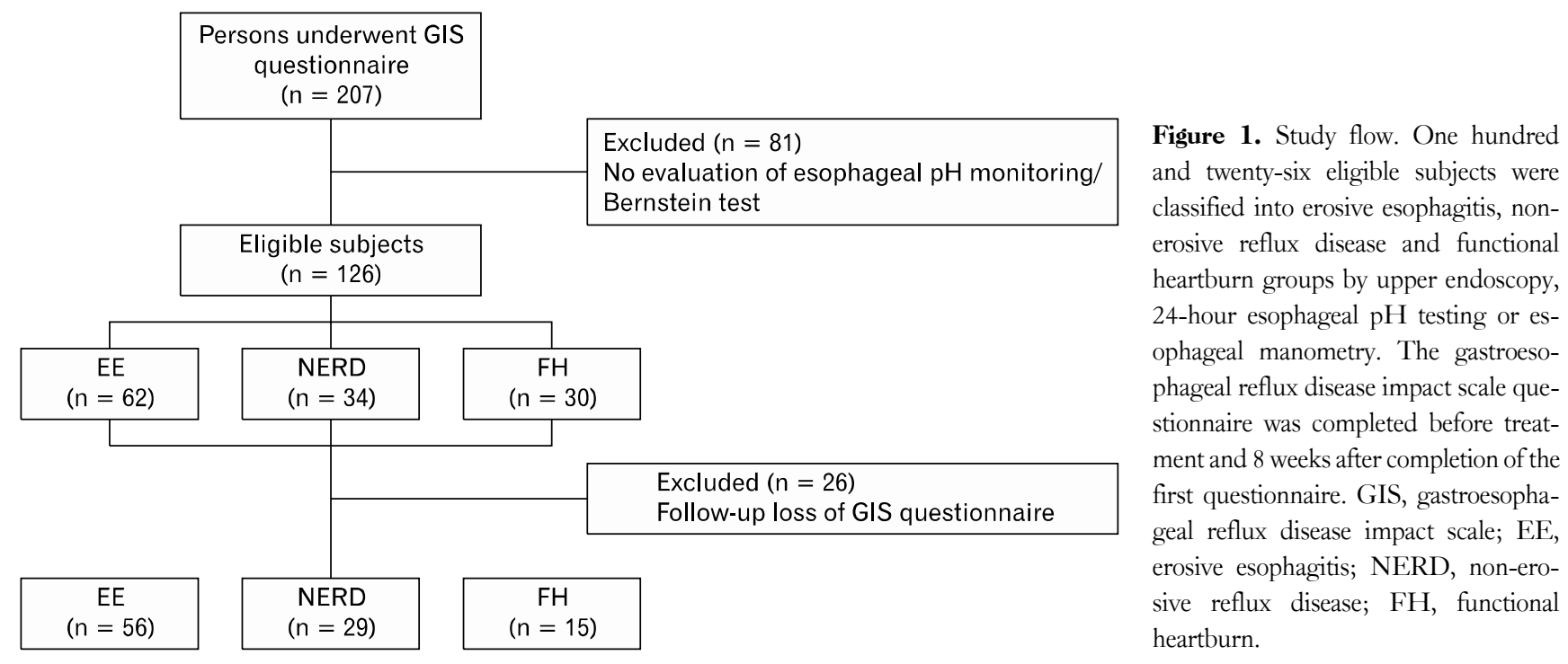




\section{Exclusion Criteria}

Patients with a history of gastrointestinal surgery, Barrett's esophagus, esophageal motility disorder, duodenal ulcer, benign gastric ulcer or gastroduodenal cancer and systemic disease requiring chronic medication (except for hypertension and diabetes mellitus) were excluded. In addition, subjects who took histamine type 2 receptor blocker or PPI within 4 weeks were excluded.

\section{Ambulatory 24-hour Esophageal pH Testing}

Twenty-four hour esophageal $\mathrm{pH}$ testing was carried out as follows: ${ }^{15}$ a single channel antimony $\mathrm{pH}$ probe (Synetics medical, Queluz, Portugal) was located $5 \mathrm{~cm}$ above the upper margin of lower esophageal pressure. Intraesophageal $\mathrm{pH}$ monitoring was recorded using an Orion $\mathrm{pH}$ recorder with the MMS (Makes Measurement Simple database 8.1 version; Enschede, Netherlands) for 24 hours. Patients were asked to record meal times, position changes and time of symptoms during the study period. Pathologic lower esophageal acid exposure was defined as an acid exposure of over $4.2 \%$ of the total time $(\mathrm{pH}<4)$ or a positive symptom index ( $>50 \%$ ). Tracings were reviewed manually by the gastroenterologist for classification of reflux episodes. Meal periods were excluded from the analysis.

\section{Bernstein Test (Acid Perfusion Test)}

The Bernstein test, which reproduces symptoms of heartburn, was performed during the esophageal manometry. ${ }^{15} \mathrm{~A}$ polyethylene catheter (outer diameter $4.5 \mathrm{~mm}$, inner diameter 0.8 $\mathrm{mm}$; Mui Scientific, Mississauga, Ontario, Canada) was positioned $5 \mathrm{~cm}$ above the upper margin of lower esophageal pressure. Then, $0.1 \mathrm{~N}$ of hydrochloric acid was perfused through the catheter at $6-7 \mathrm{~mL} / \mathrm{min}$, followed by saline (salt water) solution over a 10-minute period. A positive test was defined when the patients felt pain or discomfort similar to the GERD symptoms during acid infusion and pain or discomfort was relieved when the acid solution was replaced by saline solution. This procedure was repeated to confirm whether the test results were reproducible.

\section{Questionnaire}

The physician (NK) administered the GIS questionnaire to the patients before diagnostic evaluation. The questionnaire is comprised of 9 items including 5 questions on GERD symptoms (chest pain, heartburn, acid regurgitation, epigastric pain and hoarseness) and 4 questions on QOL. The QOL questions are these: (1) how often have you had difficulty in getting a good sleep because of heartburn or acid reflux?, (2) how often have your symptoms prevented you from eating or drinking any of the foods you like?, (3) how frequently have your symptoms kept you from being fully productive in your job or daily activities? and (4) how often do you take additional unprescribed medication other than what the physician told you to take? A modified 5-point Likert scale was utilized in GIS questionnaire to assess the detailed frequency of the symptoms (1, daily; 2, 3-4 times per week; 3, 1-2 times per week; 4, 1-2 times per month; 5, never). The factors which might be related to GERD were also analyzed i.e., (1) the presence of diabetes mellitus or hypertension, (2) alcohol consumption, (3) smoking and (4) psychiatric treatment or psychopharmacotherapy. Body mass index (BMI) and biochemical test results, including cholesterol, triglycerides, high density lipoprotein (HDL) and low density lipoprotein (LDL) levels were recorded by research assistants.

\section{Treatment and Follow-up}

The patients with GERD symptoms were treated with a standard dose of PPIs (e.g., esomeprazole, rabeprazole, pantoprazole or lansoprazole) according to the physician's choice for 8 weeks. The GIS questionnaire was repeated 8 weeks after completion of PPI therapy by the same physician (NK).

\section{Statistical Methods}

The age of the patients was categorized by decile. BMI was categorized using 23 and $25 \mathrm{~kg} / \mathrm{m}^{2}$ as cut-off points in accordance with the WHO recommendations for Asians. ${ }^{16}$ Cholesterol, triglyceride, and HDL levels were recorded using the standard clinical cut-off points $(200,150$ and $40 \mathrm{mg} / \mathrm{dL}$ [female]/50 $\mathrm{mg} / \mathrm{dL}$ [male]). The median, range, mean and SD were used for descriptive statistics. Continuous variables were compared using the ANOVA test and are presented as the mean $\pm \mathrm{SD}$. Categorical variables were compared using chi-squared test. Pearson's correlation coefficient $(r)$ was calculated to determine the correlation between the GERD symptoms and the impact of symptoms on life (QOL) by comparing the sum of scores for the GIS subscale 'GERD symptoms' and 'QOL' at baseline in 3 groups. The sum of scores was also estimated using a 5-point Likert scale. A $P$-value of less than 0.05 was considered statistically significant. Data were analyzed using the SPSS statistical software package (SPSS 15.0 for Windows; SPSS Inc, Chicago, IL, USA). 


\section{Results}

\section{Patient Characteristics}

A total of 126 subjects with GERD symptoms were finally recruited (Fig. 1): 62 patients with EE (Los Angeles grades A to $\mathrm{D}$, minimal changes were excluded) diagnosed by upper endoscopy, 34 NERD with patients positive results on 24-hour esophageal $\mathrm{pH}$ testing and/or the acid perfusion test during esophageal manometry, with no mucosal injuries including minimal change during the upper endoscopy, and 30 patients diagnosed as $\mathrm{FH}$ without any erosions by upper endoscopy and negative for the 24-hour esophageal $\mathrm{pH}$ testing and the acid perfusion test. The demographics, clinical and laboratory findings among these 3 groups are presented in Table 1 . No significant difference was observed in the age among the groups. In contrast, a significant gender difference was observed among the groups. Specifically, the proportion of men was significantly higher in EE patients than in the other 2 groups $(P<0.001)$. Alcohol consumption and smoking history were more frequent in the EE group than in the NERD and FH groups (both, $P<0.001$ ). The EE group showed hiatal hernia more frequently $(19.4 \%)$ than the NERD and $\mathrm{FH}$ groups $(8.8 \%$ and $0 \%$, respectively; $P=0.022)$. The frequency of $\mathrm{BMI} \geq 25 \mathrm{~kg} / \mathrm{m}^{2}$ was higher in the EE group (42.6\%) compared to the NERD and $\mathrm{FH}$ groups $(34.6 \%$ and $14.8 \%$, respectively; $P=0.010)$. The frequency of high triglyceride ( $\geq 150 \mathrm{mg} / \mathrm{dL}$ ) were higher in the EE group (53.8\%) compared to the NERD and FH groups (14.3\% and $40.0 \%$, respectively; $P=0.013)$. The frequency of HDL were higher in the NERD group (85.7\%) compared to the $\mathrm{EE}$ and $\mathrm{FH}$ groups (51.3\% and $13.3 \%$, respectively; $P=0.005$ ). History of psychiatric treatment and psychopharmacotherapy were more frequent in the $\mathrm{FH}$ group ( $36.7 \%$ and $50.0 \%$, respectively) than in the $\mathrm{EE}$ group $(17.7 \%$ and $24.2 \%$, respectively) or in the NERD group ( $11.8 \%$ and $26.5 \%$, respectively) (both, $P<0.005$ ). However, there was no significant difference in atrophic gastritis, hypertension, diabetes mellitus, cholesterol and LDL levels among the

Table 1. Study Subject Characteristics

\begin{tabular}{|c|c|c|c|c|}
\hline Variable category & $\begin{array}{c}\mathrm{EE} \\
(\mathrm{n}=62)\end{array}$ & $\begin{array}{l}\text { NERD } \\
(\mathrm{n}=34)\end{array}$ & $\begin{array}{c}\mathrm{FH} \\
(\mathrm{n}=30)\end{array}$ & $P$-value \\
\hline Age (mean $\pm \mathrm{SD}, \mathrm{yr})$ & $58.2 \pm 13.2$ & $55.2 \pm 10.8$ & $57.4 \pm 12.5$ & 0.509 \\
\hline Gender (men:women $[\%]$ ) & $47: 15(76: 24)$ & $12: 22(35: 65)$ & $9: 21(30: 70)$ & $<0.001$ \\
\hline Alcohol (n [\%]) & $24(40.0)$ & $5(14.7)$ & $3(10.0)$ & 0.002 \\
\hline Smoking (n [\%]) & $19(31.7)$ & $3(8.8)$ & $5(16.7)$ & 0.027 \\
\hline Hypertension (n [\%]) & $22(35.5)$ & $10(29.4)$ & $6(20.0)$ & 0.314 \\
\hline Diabetes mellitus (n [\%]) & $7(11.3)$ & $3(8.8)$ & $3(10.0)$ & 0.928 \\
\hline $\mathrm{BMI}\left(\right.$ mean $\left.\pm \mathrm{SD}, \mathrm{kg} / \mathrm{m}^{2}\right)$ & $25.1 \pm 2.9$ & $24.4 \pm 4.4$ & $22.6 \pm 2.5$ & 0.010 \\
\hline$\geq 25(\mathrm{n}[\%])$ & $20(42.6)$ & $9(34.6)$ & $4(14.8)$ & \\
\hline $23.0-24.9(\mathrm{n}[\%])$ & $16(34.0)$ & $7(26.9)$ & $6(22.2)$ & \\
\hline$<23(\mathrm{n}[\%])$ & $11(23.4)$ & $10(38.5)$ & $17(63.0)$ & \\
\hline Hiatal hernia (n [\%]) & $12(19.4)$ & $3(8.8)$ & $0(0.0)$ & 0.022 \\
\hline Endoscopic atrophic gastritis (n [\%]) & $18(29.0)$ & $7(20.6)$ & $9(30.0)$ & 0.614 \\
\hline Cholesterol (mean $\pm \mathrm{SD}, \mathrm{mg} / \mathrm{dL})$ & $182.6 \pm 30.2$ & $194.5 \pm 34.7$ & $186.4 \pm 31.3$ & 0.277 \\
\hline Triglyceride (mean $\pm \mathrm{SD}, \mathrm{mg} / \mathrm{dL})$ & $165.5 \pm 73.3$ & $108.2 \pm 68.4$ & $126.7 \pm 78.0$ & 0.013 \\
\hline$\geq 150(\mathrm{n}[\%])$ & $21(53.8)$ & $3(14.3)$ & $6(40.0)$ & \\
\hline$<150(\mathrm{n}[\%])$ & $18(46.2)$ & $18(85.7)$ & $9(60.0)$ & \\
\hline $\mathrm{HDL}($ mean $\pm \mathrm{SD}, \mathrm{mg} / \mathrm{dL})$ & $49.9 \pm 11.4$ & $60.9 \pm 13.6$ & $57.4 \pm 14.5$ & 0.005 \\
\hline$<40($ men $),<50$ (women) $(\mathrm{n}[\%])$ & $19(48.7)$ & $3(14.3)$ & $13(86.7)$ & \\
\hline$\geq 40($ men $), \geq 50($ women $)(\mathrm{n}[\%])$ & $20(51.3)$ & $18(85.7)$ & $2(13.3)$ & \\
\hline $\mathrm{LDL}($ mean $\pm \mathrm{SD}, \mathrm{mg} / \mathrm{dL})$ & $91.7 \pm 26.3$ & $102.9 \pm 25.1$ & $105.8 \pm 28.7$ & 0.135 \\
\hline Psychiatric treatment (n [\%]) & $11(17.7)$ & $4(11.8)$ & $11(36.7)$ & 0.036 \\
\hline Psychopharmacotherapy (n [\%]) & $15(24.2)$ & $9(26.5)$ & $15(50.0)$ & 0.034 \\
\hline
\end{tabular}

EE, erosive esophagitis; NERD, non-erosive reflux disease; FH, functional heartburn; BMI, body mass index; HDL, high density lipoprotein; LDL, low density lipoprotein. 
3 study groups.

\section{Comparison of Gastroesophageal Reflux Disea- se Symptoms and Quality of Life Among Ero- sive Esophagitis, Non-erosive Reflux Disease and Functional Heartburn}

Five GERD symptoms (chest pain, heartburn, acid regurgitation, epigastric pain and hoarseness) and four impacts of symptoms on life (sleep disturbance, eating problems, limitation of productive daily activities and use of additional un-prescribed medication) were analyzed by the proportion of frequency more than once a week (GIS score 3 or under). The frequency of chest pain was higher in the $\mathrm{FH}$ group (36.7\%) than in the EE group (21.0\%) and NERD group (17.6\%) $(P=0.026)$. The remaining 4 GERD symptoms of heartburn, acid regurgitation, epigastric pain and hoarseness were not significantly different among these 3 groups.

Eating problems and limitation of productive daily activities rate were higher in the $\mathrm{FH}$ group (20\% and $30 \%$, respectively) than in the EE group (3.2\% and $9.7 \%$, respectively) and NERD group ( $11.8 \%$ and $20.6 \%$, respectively) (both, $P<0.05$ ). In case of sleep disturbance the prevalence of at least once per week was higher in the NERD group (23.5\%) and FH group (16.7\%) than EE group (12.9\%) but it did not reach statistical significance. There was no statistical difference regarding use of additional un-prescribed medication among these 3 groups (Table 2).

\section{Correlation Between the Gastroesophageal Re- flux Disease Symptoms and the Impact of Symp- toms on Life (Quality of Life)}

Correlations between the GERD symptoms and the impact of symptoms on life (QOL) were evaluated by Pearson's correlation analysis. The sum of the scores on the GERD symptoms was significantly correlated with 4 questions on QOL at baseline questionnaire in the $\mathrm{EE}$ and $\mathrm{FH}$ groups (Pearson's correlation coefficient: $r=0.387[P=0.002]$ and $r=0.531[P=0.003]$, respectively) (Fig. 2), but not in the NERD group.

\section{Comparison of Responsiveness to Proton Pump Inhibitors by Gastroesophageal Reflux Disease Impact Scale Score}

The responsiveness to PPIs was estimated by subtraction of the scores on each questions between before diagnostic evaluation and after 8 weeks treatment with PPIs ${ }^{17}$ using a 5-point Likert scale, ranging from 1 (all of the time) to 5 (none), with low scores indicating a severe impairment of daily functioning. GIS after 8 weeks of PPI treatment showed improvement in all of the GERD symptoms in the EE group (all $P<0.05$ ) and acid regurgitation, epigastric pain and hoarseness in the NERD group (all $P<0.05$ ) (Table 3). In contrast, none of the GERD symptom was improved in the $\mathrm{FH}$ group. In terms of QOL, PPI treatment improved sleep disturbance in the EE group $(P=$ $0.031)$ and limitation of productive activity in the NERD group $(P=0.001)$. Again, there was no change in case of the $\mathrm{FH}$ group.

\section{Discussion}

The patients with GERD symptoms were classified into EE, NERD and FH groups based on the result of upper endoscopy, 24-hour esophageal $\mathrm{pH}$ testing or acid perfusion test in the present study. There have been few studies which compared FH with EE and NERD because of the difficulty in differentiation between NERD and FH. In our study, these 3 groups were found to be very different from each other in demographics and clinical characteristics although the presenting GERD symptoms were similar. Western reports showed that male gender, frequent hiatal hernia, and a higher BMI were more common in the EE group

Table 2. Gastroesophageal Reflux Disease Symptoms and Quality of Life Measured by Gastroesophageal Reflux Disease Impact Scale Questionnaire

\begin{tabular}{lcccc}
\hline $\begin{array}{c}\text { GERD symptoms } \\
(\mathrm{n}[\%])\end{array}$ & $\begin{array}{c}\mathrm{EE} \\
(\mathrm{n}=62)\end{array}$ & $\begin{array}{c}\text { NERD } \\
(\mathrm{n}=34)\end{array}$ & $\begin{array}{c}\mathrm{FH} \\
(\mathrm{n}=30)\end{array}$ & $P$-value \\
\hline Chest pain & $13(21.0)$ & $6(17.6)$ & $11(36.7)$ & 0.026 \\
Heartburn & $23(37.1)$ & $10(29.4)$ & $12(40.0)$ & 0.296 \\
Acid regurgitation & $29(46.8)$ & $17(50.0)$ & $13(43.3)$ & 0.212 \\
Epigastric pain & $14(22.6)$ & $15(44.1)$ & $10(33.3)$ & 0.131 \\
Hoarseness & $16(25.8)$ & $13(38.2)$ & $14(46.7)$ & 0.172 \\
Sleep disturbance & $8(12.9)$ & $8(23.5)$ & $5(16.7)$ & 0.107 \\
Eating problems & $2(3.2)$ & $4(11.8)$ & $6(20.0)$ & 0.032 \\
Limitation of & $6(9.7)$ & $7(20.6)$ & $9(30.0)$ & 0.023 \\
$\quad \begin{array}{l}\text { productive daily } \\
\text { activities }\end{array}$ & & & & \\
Use of additional & $4(6.5)$ & $2(5.9)$ & $1(3.3)$ & 0.799 \\
$\quad \begin{array}{l}\text { un-prescribed } \\
\text { medication }\end{array}$ & & & & \\
\hline
\end{tabular}

Five gastroesophageal reflux disease (GERD) symptoms (chest pain, heartburn, acid regurgitation, epigastric pain and hoarseness) and 4 impact of symptoms on life (sleep disturbance, eating problems, limitation of productive daily activities and use of additional un-prescribed medication) were analyzed by the proportion of frequency more than once a week (GERD impact scale score 3 or under). EE, erosive esophagitis; NERD, non-erosive reflux disease; $\mathrm{FH}$, functional heartburn. 

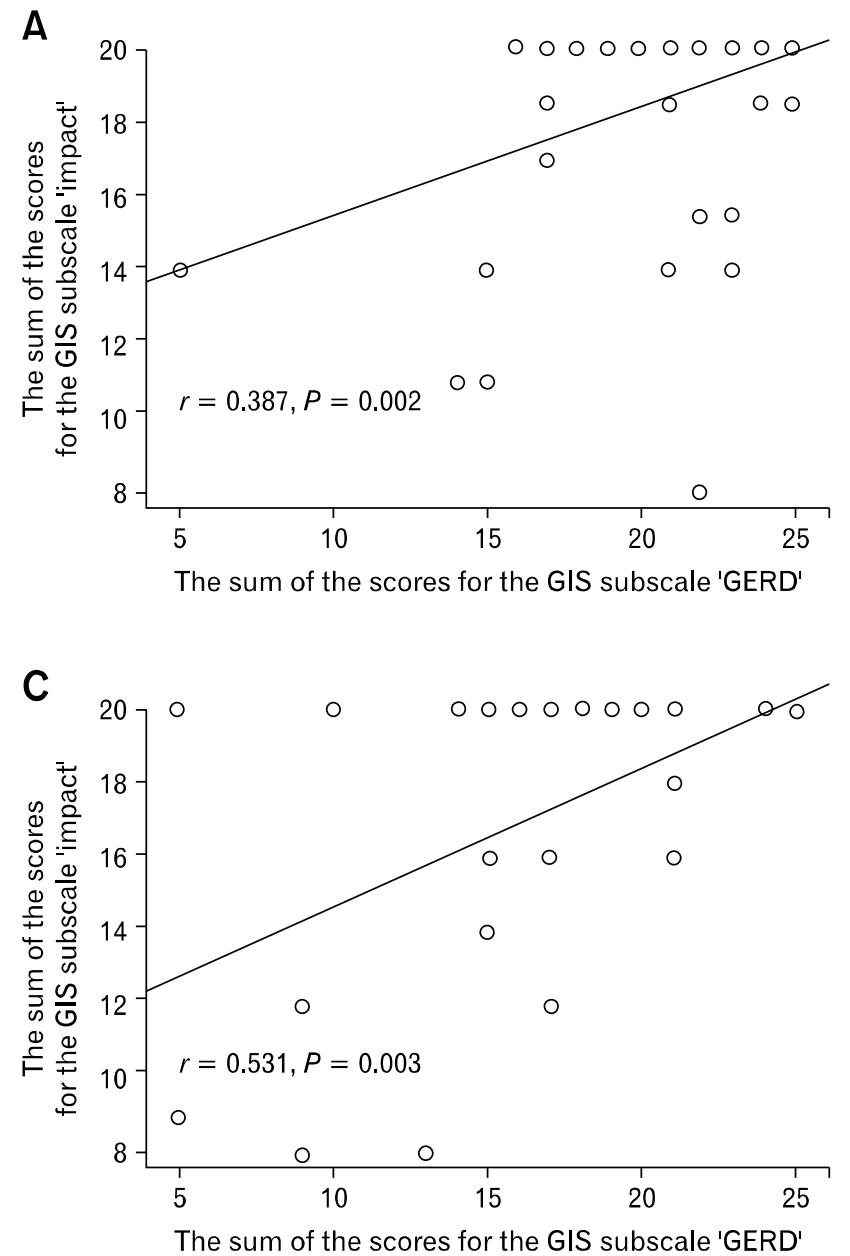

than in the NERD group, ${ }^{18}$ similar to our study. EE patients were reported to be older than $\mathrm{NERD}^{19}$ but our study showed that the age of EE group was similar to that of NERD and $\mathrm{FH}$ group, which was also observed in the previous Korean report. ${ }^{20}$ Female gender was predominant in NERD and $\mathrm{FH}$ in the present study, a frequent finding in functional disorders. ${ }^{21-23}$ Our study also showed that alcohol consumption, smoking history, the presence of hiatal hernia, BMI $\geq 25 \mathrm{~kg} / \mathrm{m}^{2}$ and triglyceride levels ( $\geq 150 \mathrm{mg} / \mathrm{dL}$ ) were significantly more common in patients with $\mathrm{EE}$ than in those with NERD and $\mathrm{FH}$, supporting an association of high $\mathrm{BMI}^{24}$ or obesity with EE. ${ }^{25}$ In addition, hiatal hernia, a significant risk factor for EE, was found to be significantly associated with an increased BMI. ${ }^{26}$ On the other hand, anxiety and depression tended to be more prevalent in $\mathrm{FH}$ patients than in EE or NERD patients. ${ }^{20}$ In addition, patients whose heartburn was not correlated well with acid reflux events demonstrated greater anxiety and somatization scores as well as poorer social support than those with acid reflux-related symp-

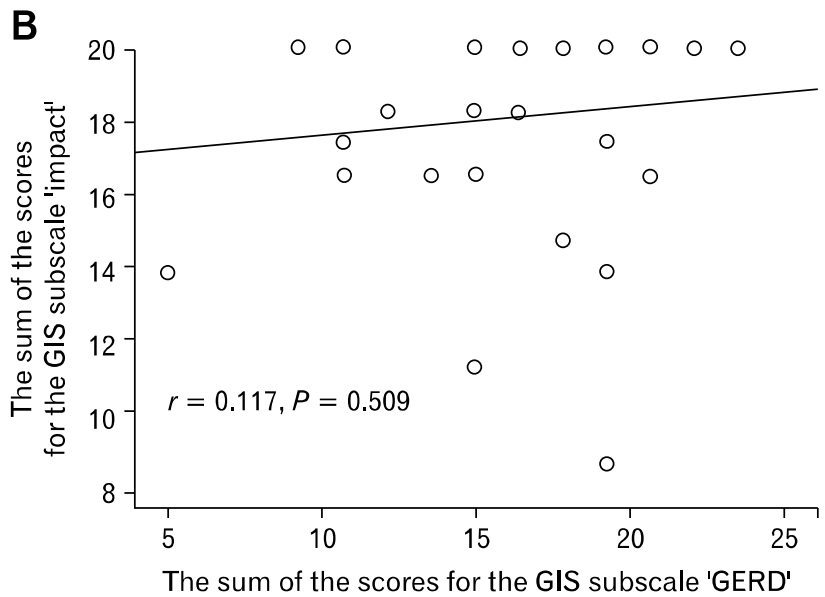

Figure 2. Correlations between the sum of scores for the gastroesophageal reflux disease (GERD) impact scale subscale 'GERD symptoms' and 'Quality of life' at baseline in patients with erosive esophagitis (A), non-erosive reflux disease (B) and functional heartburn $(\mathrm{C})$. Pearson's correlation coefficient of erosive esophagitis, $r=0.387(P=0.002)$; non-erosive reflux disease, $r=0.117(P=$ 0.509); functional heartburn, $r=0.531(P=0.003)$. GIS, GERD impact scale; QOL, quality of life.

toms. ${ }^{27}$ The history of both psychiatric treatment and psychopharmacotherapy was more frequent in patients with $\mathrm{FH}$ than in those with EE or NERD in the present study. This result suggests that psychological co-morbidity can modulate esophageal perception and cause patients to perceive low intensity esophageal stimuli as being painful. ${ }^{28}$ Otherwise there was no difference with regards to endoscopic atrophic gastritis, hypertension, diabetes mellitus, cholesterol and LDL among the 3 groups in our sample, similar to a number of studies, ${ }^{29-31}$ showing that these factors are not peculiar to any of our subgroups.

Several questionnaires have been developed for the assessment of GERD symptoms in recent years. ${ }^{11,32,33}$ However, the impact of symptoms on everyday life was not included in most of the questionnaires. GIS questionnaire has been developed with the main intent as a communication tool between patients and their physicians. It is a simple, one page questionnaire for doctors to check the frequency of reflux symptoms and their effect on QOL in primary care, helping clinicians to ask GERD symp- 
Table 3. Changes in Gastroesophageal Reflux Disease Impact Scale Scores After Proton Pump Inhibitor Treatment for 8 Weeks

\begin{tabular}{lcccc}
\hline \multicolumn{1}{c}{ Scale $($ mean \pm SD $[P$-value $])$} & EE $(\mathrm{n}=56)$ & NERD $(\mathrm{n}=29)$ & FH $(\mathrm{n}=15)$ & $P$-value \\
\hline Chest pain & $0.34 \pm 1.16(0.033)$ & $-0.03 \pm 1.80(0.919)$ & $0.60 \pm 1.24(0.082)$ & 0.031 \\
Heartburn & $0.91 \pm 1.23(0.000)$ & $0.31 \pm 1.69(0.332)$ & $-0.47 \pm 1.25(0.169)$ & 0.856 \\
Acid regurgitation & $0.89 \pm 1.34(0.000)$ & $0.93 \pm 2.03(0.020)$ & $0.20 \pm 1.15(0.510)$ & 0.034 \\
Epigastric pain & $0.45 \pm 1.41(0.022)$ & $0.76 \pm 1.53(0.012)$ & $0.27 \pm 1.10(0.364)$ & 0.285 \\
Hoarseness & $0.45 \pm 1.63(0.045)$ & $1.10 \pm 1.63(0.001)$ & $0.47 \pm 1.20(0.380)$ & 0.075 \\
Sleep disturbance & $0.23 \pm 0.79(0.031)$ & $0.62 \pm 1.86(0.083)$ & $0.27 \pm 1.03(0.334)$ & 0.166 \\
Eating problems & $0.00 \pm 0.56(1.000)$ & $0.10 \pm 0.41(0.184)$ & $0.53 \pm 1.40(0.164)$ & 0.021 \\
Limitation of productive daily activities & $0.14 \pm 0.84(0.209)$ & $1.03 \pm 1.50(0.001)$ & $0.80 \pm 1.66(0.082)$ & 0.026 \\
Use of additional un-prescribed medication & $0.18 \pm 0.90(0.142)$ & $0.10 \pm 0.77(0.477)$ & $0.00 \pm 1.51(1.000)$ & 0.839 \\
\hline
\end{tabular}

The number was expressed by 5 -point Likert scale, ranging from 1 (all of the time) to 5 (never). The responsiveness to proton pump inhibitors (PPIs) was estimated by subtraction of scores on each questions between before diagnostic evaluation and after 8 week treatment with PPIs in patients with erosive esophagitis, non-erosive reflux disease or functional heartburn using a 5 -point Likert scale. $P$-values of each symptom (intra-group analysis) were given in parentheses. EE, erosive esophagitis; NERD, non-erosive reflux disease; $\mathrm{FH}$, functional heartburn.

toms quickly and to appropriately treat patients' symptoms. ${ }^{14}$ To evaluate the clinical efficacy of GIS in the tertiary hospital, GERD symptoms and the impact of symptoms were compared in our 3 groups with GERD symptoms using a GIS questionnaire. About $65 \%$ of EE patients had not experienced typical GERD symptoms like heartburn or acid regurgitation. ${ }^{34}$ The main reason of higher number of patients without typical GERD symptoms in Korea is that many of the EE patients reported were diagnosed incidentally by health examinations. However, we only enrolled the patients that visited the hospital for GERD symptoms. So, all enrolled patients had one or more GERD symptoms. Interestingly, the prevalence of chest pain and eating problems and limitation of productive daily activities were significantly higher in the $\mathrm{FH}$ group than the EE and NERD groups. GERD symptoms and effects on daily life in $\mathrm{FH}$ patients in our study could be explained by psychological co-morbidity modulating esophageal perception. ${ }^{28}$ Recent studies performed mainly in Western countries demonstrated a bidirectional relationship between GERD and sleep where night-time reflux leads to sleep deprivation and sleep deprivation per se can exacerbate GERD by enhancing perception of intra-esophageal stimuli. ${ }^{35-37}$ In addition, medical treatment with PPIs of nighttime GERD improved sleep disturbances. ${ }^{38-41}$ However, there have been no reports regarding a bidirectional relationship between GERD and sleep in Korea, so far, where the incidence of GERD is not so high in comparison to Western countries. Interestingly, the prevalence of sleep disturbance due to GERD symptoms at least once per week was higher in the NERD (23.5\%) and FH (16.7\%) than in the EE (12.9\%) but without statistical significance in the present study. Since this could be a result of the small sample size, there is a possibility of bidirectional relationship between GERD and sleep in a large population, which could be worth investigating.

Classical GERD symptoms no longer provide a complete description of patient disability related to GERD and FH. The limitations of symptom assessments have been emphasized recently by $\mathrm{McColl} \mathrm{et} \mathrm{al.}{ }^{42}$ It is clear that a new paradigm for the accurate assessment of the true impact of GERD on an individual patient is needed. Accordingly QOL has become a component of the definition of GERD and is essential to the evaluation of therapeutic interventions. One of the benefits of the GIS questionnaire is that it can monitor the GERD symptoms and QOL at a glance in an easily accessible manner. When the correlation between the GERD symptoms and impact of symptoms was compared in our study, there was a close positive correlation between 2 factors in the EE and FH groups. Contrary to our expectations, however, there was no correlation in the NERD group, which could be clarified in large population based studies. In spite of this, the positive correlation in the $\mathrm{EE}$ and $\mathrm{FH}$ groups suggests the usefulness of GIS questionnaire.

GIS has not been formally validated as a tool to monitor the response of GERD symptoms and QOL to PPI treatment. Our trial to compare the responsiveness of PPIs in subjects with GERD symptoms using a GIS questionnaire is mainly from the practical viewpoint. That is, the clinicians should assess the patient's short term response to GERD treatment effectively, especially in the clinical situation of South Korea. It is very interesting that the response to PPI was found to be different among three groups. That is, chest pain was more improved in the FH group, but acid regurgitation more improved in the EE and NERD groups. In case of QOL, eating problems and limitation of pro- 
ductive daily activities were more improved in the $\mathrm{FH}$ group and in the NERD group, respectively. The reason for this different response might be related to the initial severity of GERD symptoms in 3 groups. That is, in $\mathrm{FH}$ the prominent symptom was chest pain and this symptom was clearly improved by PPI. The result that an atypical symptom like a chest pain was more improved in $\mathrm{FH}$ after PPI treatment suggests a probable overlap between $\mathrm{FH}$ and functional dyspepsia. Chest pain has been reported in patients with functional dyspepsia ${ }^{43}$ and PPI was also superior in relieving the symptoms of functional dyspepsia. ${ }^{44}$ Similarly, improvement of QOL like eating problems or limitation of productive daily activities in $\mathrm{FH}$ could be explained as above. Taken together these results provide another proof that GIS questionnaire could be a useful communication tool between patients and their physicians. We could not suggest 'cut-off value' for responder or non-responder. However, using each score, doctors can detect uncomfortable symptoms of patients and choose appropriate treatment. Also, by comparing total score, doctors can learn the patient's short-term response to GERD treatment. So far, few studies compared the characteristics of EE, NERD and FH groups, ${ }^{29,45}$ but there has been no study comparing the characteristics of the 3 groups using GIS questionnaire.

Our study has several limitations. That is, the number of patients was small, especially in the case of NERD and FH. However, the diagnosis of NERD and FH is based on Bernstein test and 24-hour esophageal $\mathrm{pH}$ meter. It is very difficult to persuade patients to undertake these 2 studies because GERD symptoms are not so critical and PPI test could be used instead of these two studies. However, these strict diagnostic criteria became useful for the differentiation of EE, NERD and FH. Second, follow-up number after PPI therapy became smaller. As the NERD or FH is not life threatening, there is a possibility of follow-up loss in both of the patients who had GERD symptoms improved or not responded. However, there was different response in these 3 groups after 8 weeks of PPI therapy in the present study.

In conclusion, the GERD and impact of symptom pattern as well as demographic and clinical characteristics were different among EE, NERD and FH. In addition, our study is the first study which suggested the usefulness of GIS questionnaire in the follow-up after PPI therapy among patients with EE, NERD or FH.

\section{References}

1. Vakil N, van Zanten SV, Kahrilas P, Dent J, Jones R, Global
Consensus Group. The Montreal definition and classification of gastroesophageal reflux disease: a global evidence-based consensus. Am J Gastroenterol 2006;101:1900-1920.

2. Kahrilas PJ. Gastroesophageal reflux disease. JAMA 1996;276: 983-988.

3. Spechler SJ. Epidemiology and natural history of gastro-oesophageal reflux disease. Digestion 1992;51(suppl 1):24-29.

4. Lundell LR, Dent J, Bennett JR, et al. Endoscopic assessment of oesophagitis: clinical and functional correlates and further validation of the Los Angeles classification. Gut 1999;45:172-180.

5. Dent J, Brun J, Fendrick AM, et al. An evidence-based appraisal of reflux disease management - the Genval Workshop Report. Gut 1999;44(suppl 2):S1-S16.

6. Clouse RE, Richter JE, Heading RC, Janssens J, Wilson JA. Functional esophageal disorders. Gut 1999;45(suppl 2):II31-II36.

7. Galmiche JP, Clouse RE, Bálint A, et al. Functional esophageal disorders. Gastroenterology 2006;130:1459-1465.

8. Wiklund I. Review of the quality of life and burden of illness in gastroesophageal reflux disease. Dig Dis 2004;22:108-114.

9. Wiklund I, Talley NJ. Update on health-related quality of life in patients with gastroesophageal reflux disease. Expert Rev Pharmacoecon Outcomes Res 2003;3:341-350.

10. Prasad M, Rentz AM, Revicki DA. The impact of treatment for gastro-oesophageal reflux disease on health-related quality of life: a literature review. Pharmacoeconomics 2003;21:769-790.

11. Shaw MJ, Talley NJ, Beebe TJ, et al. Initial validation of a diagnostic questionnaire for gastroesophageal reflux disease. Am J Gastroenterol 2001;96:52-57.

12. Jones R, Junghard O, Dent J, et al. Development of the GerdQ, a tool for the diagnosis and management of gastro oesophageal reflux disease in primary care. Aliment Pharmacol Ther 2009;30:10301038.

13. Revicki DA, Wood M, Wiklund I, Crawley J. Reliability and validity of the Gastrointestinal Symptom Rating Scale in patients with gastroesophageal reflux disease. Qual Life Res 1998;7:75-83.

14. Jones R, Coyne K, Wiklund I. The gastro-oesophageal reflux disease impact scale: a patient management tool for primary care. Aliment Pharmacol Ther 2007;25:1451-1459.

15. Lee E, Kim N, Lee S, et al. Comparison of risk factors and clinical responses to proton pump inhibitors in patients with erosive oesophagitis and non erosive reflux disease. Aliment Pharmacol Ther 2009; $30: 154-164$.

16. Wong WM, Lai KC, Lam KF, et al. Onset and disappearance of reflux symptoms in a Chinese population: a 1 year follow up study. Aliment Pharmacol Ther 2004;20:803-812.

17. van Zanten SV, Wahlqvist $P$, Talley NJ, et al. Randomised clinical trial: the burden of illness of uninvestigated dyspepsia before and after treatment with esomeprazole - results from the STARS II study. Aliment Pharmacol Ther 2011;34:714-723.

18. Carlsson R, Dent J, Watts R, et al. Gastro-oesophageal reflux disease in primary care: an international study of different treatment strategies with omeprazole. International GORD Study Group. Eur J Gastroenterol Hepatol 1998;10:119-124.

19. Collen MJ, Abdulian JD, Chen YK. Gastroesophageal reflux disease in the elderly: more severe disease that requires aggressive therapy. Am J Gastroenterol 1995;90:1053-1057. 
20. Lee KJ, Kwon HC, Chng JY, Cho SW. Demographic, clinical, and psychological characteristics of the heartburn groups classified using the Rome III criteria and factors associated with the responsiveness to proton pump inhibitors in the gastroesophageal reflux disease group. Digestion 2009;79:131-136.

21. Bolling-Sternevald E, Carlsson R, Aalykke C, et al. Self-administered symptom questionnaires in patients with dyspepsia and their yield in discriminating between endoscopic diagnoses. Dig Dis 2000;20:191-198.

22. Welén K, Faresjö A, Faresjö T. Functional dyspepsia affects women more than men in daily life: a case-control study in primary care. Gend Med 2008;5:62-73.

23. Flier $\mathrm{SN}$, Rose $\mathrm{S}$. Is functional dyspepsia of particular concern in women\&quest; a review of gender differences in epidemiology, pathophysiologic mechanisms, clinical presentation, and management. Am J Gastroenterol 2006;101(12 suppl):S644-S653.

24. Corley DA, Kubo A, Zhao W. Abdominal obesity, ethnicity, and gastroesophageal reflux symptoms. Gut 2007;56:756-762.

25. Lee HL, Eun CS, Lee OY, et al. Association between GERD-related erosive esophagitis and obesity. J Clin Gastroenterol 2008;42: 672-675.

26. Wilson LJ, Ma W, Hirschowitz BI. Association of obesity with hiatal hernia and esophagitis. Am J Gastroenterol 1999;94:2840-2844.

27. Johnston BT, Lewis SA, Collins JS, McFarland RJ, Love AH. Acid perception in gastro-oesophageal reflux disease is dependent on psychosocial factors. Scand J Gastroenterol 1995;30:1-5.

28. Trimble KC, Pryde A, Heading RC. Lowered oesophageal sensory thresholds in patients with symptomatic but not excess gastro-oesophageal reflux: evidence for a spectrum of visceral sensitivity in GORD. Gut 1995;37:7-12.

29. Labenz J, Jaspersen D, Kulig M, et al. Risk factors for erosive esophagitis: a multivariate analysis based on the ProGERD study initiative. Am J Gastroenterol 2004;99:1652-1656.

30. Sarnelli G, De Giorgi F, Efficie E, et al. Correlation between oesophageal acid exposure and dyspeptic symptoms in patients with nonerosive reflux disease. Eur J Gastroenterol Hepatol 2008;20:264268.

31. Savarino E, Pohl D, Zentilin P, et al. Functional heartburn has more in common with functional dyspepsia than with non-erosive reflux disease. Gut 2009;58:1185-1191.

32. Carlsson R, Dent J, Bolling-Sternevald E, et al. The usefulness of a structured questionnaire in the assessment of symptomatic gastroesophageal reflux disease. Scand J Gastroenterol 1998;33:1023-1029.

33. Manterola C, Muñoz S, Grande L, Bustos L. Initial validation of a questionnaire for detecting gastroesophageal reflux disease in epidemiological settings. J Clin Epidemiol 2002;55:1041-1045.

34. Kim N, Lee SW, Cho SI, et al. The prevalence and risk factors of erosive oesophagitis and non-erosive reflux disease: a nationwide multi-centre prospective study in Korea. Aliment Pharmacol Ther 2008;27:173-185

35. Schey R, Dickman R, Parthasarathy S, et al. Sleep deprivation is hyperalgesic in patients with gastroesophageal reflux disease. Gastroenterology 2007;133:1787-1795.

36. Jung HK, Choung RS, Talley NJ. Gastroesophageal reflux disease and sleep disorders: Evidence for a causal link and therapeutic implications. J Neurogastroenterol Motil 2010;16:22-29.

37. Orr WC, Goodrich S, Fernström P, Hasselgren G. Occurrence of nighttime gastroesophageal reflux in disturbed and normal sleepers. Clin Gastroenterol Hepatol 2008;6:1099-1104.

38. Johnson DA, Orr WC, Crawley JA, et al. Effect of esomeprazole on nighttime heartburn and sleep quality in patients with GERD: a randomized, placebo-controlled trial. Am J Gastroenterol 2005;100: 1914-1922.

39. Orr WC, Goodrich S, Robert J. The effect of acid suppression on sleep patterns and sleep-related gastro-oesophageal reflux. Aliment Pharmacol Ther 2005;21:103-108.

40. Rackoff A, Agrawal A, Hila A, Mainie I, Tutuian R, Castell DO. Histamine-2 receptor antagonists at night improve gastroesophageal reflux disease symptoms for patients on proton pump inhibitor therapy. Dis Esophagus 2005;18:370-373.

41. Robinson M, Rodriguez-Stanley S, Ciociola AA, et al. Control of nocturnal gastric acidity: a role for low dose bedtime ranitidine to supplement daily omeprazole. Dig Dis Sci 2002;47:265-273.

42. McColl E, Junghard O, Wiklund I, Revicki DA. Assessing symptoms in gastroesophageal reflux disease: how well do clinician's assessments agree with those of their patients? Am J Gastroenterol 2005;100:11-18.

43. Masanori H, Kazunori M, Hiroshi Y, et al. Esophageal motility and psychiatric fctors in functional dyspepsia patients with or without pain. Dig Dis Sci 1999;44:2094-2098.

44. Talley NJ, Meineche-Schmidt V, Paré P, et al. Efficacy of omeprazole in functional dyspepsia: double-blind, randomized, plac-controlled trials (the Bond and Opera studies). Aliment Pharmacol Ther 1998;12:1055-1065.

45. Schey R, Shapiro M, Navarro-Rodriguez T, et al. Comparison of the different characteristics of sensed reflux events among different heartburn groups. J Clin Gastroenterol 2009;43:699-704. 